\title{
An Outreach Experience With Cleft Lip/Palate Surgery in selected Hospitals in Kenya
}

Authors: Wanjala $\mathbf{N}^{\mathbf{1}}$, MMed and Khainga $\mathbf{S}^{\mathbf{1 , 2}}$, MMed, Affiliations: 1.Kenyatta National Hospital, Nairobi, Kenya 2. University of Nairobi Correspondence: Dr. Nangole Wanjala, Kenyatta National Hospital. nangole2212@yahoo.com

\section{Abstract}

\section{Objective}

To describe the presentation and surgical care of patients managed for cleft lips and palates during a surgical outreach program..

Study design

A five year retrospective chart study of the patients operated on between January 2005 to the 31st December 2009 in selected hospitals in Kenya.

\section{Setting}

Smile train-facilitated surgical outreach programs at the following hospitals: St Elizabeth Mission Hospital Mukumu, St Francis Mission Hospital, Mwiki, Embu Provincial General hospital, Isiolo District Hospital.and Alupe Subdistrict Hospital.

Subjects

One hundred and sixty three patients with cleft lips and palates.

\section{Results}

The male female ratio was 1.3 to 1 . Left unilateral cleft lip was the most common malformation (34.6\% of the patients) with modified Millards repair the most frequent surgical procedure. More than $30 \%$ of the patients operated on had attained their fifth birthday. There were eight complications for every 100 procedures. Palatal fistulae were the most common complications.

\section{Conclusion}

The overall pattern of deformity encountered and the morbidity profile correlate with other studies. There is need to intensify more outreach programs to capture younger patients and address the backlog of cleft cases in the community.

\section{Introduction}

Cleft lips and palates are common congenital malformations with variable prevalences. High prevalence rates have been quoted for native Americans, Orientals, Caucasians and the blacks in that order $(1,2)$. Both hereditary and environmental factors are thought to be important in the pathogenesis.

The ideal treatment of cleft lip and palate involves a multidisciplinary team approach, comprising plastic surgeons, maxillofacial surgeons, speech pathologists, otolaryngologists, among others $(3,4)$ This treatment would also involve multiple stages of surgeries and revisits commencing from neonatal life to early adulthood. In the developing countries, this management approach is difficult if not impossible to craft. Compounding the problem of large disease burden are the twin challenges of few health personnel and poverty. Surgical outreaches remain a practical option to confront this problem.

The outreach programs mobilize skilled staff out of their usual work stations to go to ill-equipped and staffed rural facilities. A good outreach program requires an effective working relation between the visiting surgeons and the local hospital staffs. The hospital staff mobilize the patients as well as oversee the postoperative care once the outreach team leaves the site.The local team also ensures proper documentation and follow up for the patients

The authors have been involved in the "Smile Train" outreach program for the last five years. This paper describes that experience in various facilities in Kenya.

\section{Patients and Method}

This study was a retrospective chart review of the records of patients operated on by the authors at the participating hospitals. The outreach program was facilitated by Smile Train International, a non-governmental organization with regional offices in Nairobi Kenya. The following centers were included: St Elizabeth Mission Hospital Mukumu, St FrancisMission Hospital Mwiki,Embu Povincial Gen Hospital, Isiolo district Hospital and Alupe Subdistrict Hospital.

All files for patients operated on for cleft lips/palates between January 2005 and 31st December 2009 were reviewed for demographics, types of defects, timing of surgery, procedures performed and complications en- 
countered. Supplementary data was abstracted from the operating theatre registers and the Smile Train data base in Nairobi.

Cases with inadequate data were excluded from the study. Data were analyzed by the SPSS computer software for descriptive statistics.

\section{Results}

Data on 163 patients out of a total of 186 patients operated on during the study period were analyzed. Adequate information could not be retrieved for 23 patients and therefore were excluded. The male to female ratio for the patients was 1.3 to 1 .The age range was 2.5 months to 28 years with a mean age of 4.8 years. The modal age range was $6-9$ months. Fifty six patients $(34.4 \%)$ were older than 5 years at the time of surgery (table 1 ).

A total of 187 defects in 163 patients were recorded. Left unilateral cleft lip comprised 36.4 percent of the defects while bilateral cleft lips were 18.7 percent of the defects (table 2).

Modified Millard's repair was used for all the unilateral cleft lips while the Manchester repair was the technique for the majority of bilateral cleft lips. Unipedicle mucoperiosteal flaps were most commonly used surgical procedures for the cleft palate (table 3 ).

There were 14 complications following 177 procedures (Table 4). Half of the complications were palatal fistulae encountered in seven of 28 patients who underwent repairs for complete cleft palates.

\section{Discussion}

The pattern of cleft deformities in this study is consistent with previous accounts.

Left unilateral cleft lip accounted for 36.4 percent, bilateral cleft lips $18.7 \%$ and right unilateral cleft lips $17.6 \%$ percent. Many studies have demonstrated left unilateral clefts to be more common than the right unilateral clefts (5-8). An inconsistent result is the lower prevalence $(14 \%)$ of solitary cleft palates in our series compared to $30 \%$ in published series (6-7). Although a relatively lower turnout for patients with palatal defects as opposed to patients with cleft lips could explain this discrepancy, more studies need to be done in this region to determine whether this is an isolated case or is a true reflection of the palatal defects in our community.

Cleft deformities in this study were found to be more common in males than females with a male female ratio

\begin{tabular}{lll} 
Age range & Frequency & Percentage \\
\hline $0-3$ months & 6 & 3.7 \\
\hline $3-6$ months & 14 & 8.6 \\
\hline $6-9$ months & 36 & 22 \\
\hline $9-12$ months & 14 & 8.6 \\
\hline $1-2$ years & 16 & 9.8 \\
\hline $2-5$ years & 21 & 12.9 \\
\hline $5-10$ years & 18 & 11.0 \\
\hline $10-20$ years & 21 & 12.9 \\
\hline$>20$ years & 17 & 10.5 \\
\hline Total & 163 & 100 \\
\hline
\end{tabular}

Table 1; Age presentation for the patients operated on

of 1.3 to 1 . Wanjeri et al in Kenya(5), Masaki et al. in Japan(6), and Mossey et al. in Sweden(7) all demonstrated cleft deformities to be more common in the males with a ratio ranging from 1.2- 1.5 to 1. The reason for this remain unclear.

The median age group at the time of surgery was 6-9 months of age, accounting for $22 \%$ of the patients operated on. Only a small percentage of the patients had their surgeries (8.3\%) before 6 months of age, with only about 3 percent less than 3 month of age.

The optimal time to carry out cleft lip and palate surgery varies from centre to centre. In centres with good paediatric anaesthesia, surgery can be performed in early neonatal period. The rule of "ten" i.e, 10 weeks, 10 pounds, haemoglobin of ten and 10 months , 10 kilogram and a haemoglobin of 10 is a general guiding principle for the timing of lip and palate surgery respectively. Early repair of cleft lip is advantageous to the parents and the child due to the psychosocial trauma attributed to this condition. Early repair of cleft palate allows for normal speech development (7). There seems to be no evidence that early palate surgery retards mid-face growth resulting into mid-face retrusion, as previously thought (9).

A significant proportion (34\%) of the defects were after the operated patients' fifth birthdays. One tenth of the patients were adults. This delayed treatment reflects limited access to the specialist service, a fact that reinforces the need and relevance of specialist outreach services. The modified Millard's technique commonly used in this study is the commonest technique for cleft lip repair especially in the United States of America and Europe $(10,11)$. For bilateral clefts, the Manchester and Mullikens techniques are options to consider. The advantages of the Mullikens procedure is the collumella lengthening with a superior nose repair.(12,13). Its drawback is the extensive dissection over the nose as well as the long incisions 


\section{An Outreach Experience With Cleft Lip/Palate Surgery in selected Hospitals in Kenya}

\section{Wanjala N, Khainga S}

\begin{tabular}{lllll} 
Defect & Incomplete Cleft & Complete cleft & Total & $\%$ \\
\hline Rt unilateral cleft lip & 8 & 25 & 33 & 17.6 \\
\hline Lt unilateral cleft lip & 14 & 54 & 68 & 36.4 \\
\hline Bilateral cleft lip & 4 & 31 & 35 & 18.7 \\
\hline Cleft palate & Soft palate & Complete cleft palate & \\
\hline Cleft palate with lip defects & 4 & 20 & 24 & 12.8 \\
\hline Cleft palate with no lip defect & 3 & 24 & 27 & 14.4 \\
\hline TOTAL & 33 & 154 & 187 & 100
\end{tabular}

Table 2: Summary of the defect encountered during the study.

\begin{tabular}{llll} 
Procedure & Diagnosis & Frequency & \% \\
\hline Modified Millard & Unilateral cleft lip & 101 & 57 \\
\hline Manchester repair & Bilateral cleft lip & 22 & 12.4 \\
\hline Mullikens repair & Bilateral cleft lip & 13 & 7.3 \\
\hline Furlows z plasty & Soft palate & 5 & 2.8 \\
\hline Turnover flaps closure & Palatal fistulae & 6 & 3.4 \\
\hline Unipedicle Mucoperiostal flap & Complete cleft palate & 28 & 15.8 \\
\hline Others & Palatal fistulae & 2 & 1.3 \\
\hline Total & & 177 & 100 \\
\hline
\end{tabular}

Table 3: Surgical Procedures performed

\begin{tabular}{llcccc} 
Surgical procedure & Frequency & Wound sepsis & Bleeding & Dehiscence & $\begin{array}{l}\text { Fistula } \\
\text { formation }\end{array}$ \\
\hline Modified Millards & 101 & 2 & & & \\
\hline Mullikens & 13 & 1 & & & \\
\hline Manchester & 22 & 1 & & & \\
\hline Unipedicle mucoperiostal & 28 & & 2 & 1 & 7 \\
\hline Others & 8 & & & & \\
\hline Total & 177 & 4 & 2 & 1 & 7 \\
\hline Percentage & & 28.6 & 14.2 & 7.1 & 50 \\
\hline
\end{tabular}

Table 4 complications encountered

as compared to the Manchester technique. Many techniques have been described for the palatal surgery ,including two stage procedure $(14,15)$. In our practice, a single stage unipedicle mucoperiosteal flap with a nasal mucosal back cut at the hard palate is usual.

The overall complication rate in the current study also compares favourably with other studies reported in literature. We did not determine the reasons for the complications which could include the weight at the time of surgery (16) or cross infections in the post-operative period (17).

In conclusion, the overall pattern of deformity in this study resembled other studies. Although surgical intervention for majority of the cases was 'delayed', the morbidity profile remains acceptable. More surgical outreach programs can address the huge burden of cleft cases outside central health facilities.

\section{Reference}

1. Tolarova MM,Cervella J Classification and birth prevelance of orafacial clefts. Amer J. Genet:1998;75;126-137

2. Croen L.A,Shaw G.M. et al Racial and ethnic variations in the prevalence of orofacial clefts in california 1983-1992 Amer J Med GenAm et 1998;(79) 42-47

3. Robin $\mathrm{N}$ H,Baty $\mathrm{H}$ et al The multidisciplinary evaluation and management of cleft lip and palate Southmed J.2006 oct 99(10)1111-20

4. Takehiko S, Atsushi Y et al Multidisciplinary management for cleft lip and palate patients.A team approach from tohoka university japanese Journal of plastic and reconstructive Surgery. 2002,45 (2) pp 117-123

5. Wanjeri JK, Wachira JM. Cleft Lip and Palate:A descriptive comparative retrospective and prospective study of patients with cleft deformities managed at 2 hospitals in Kenya. J Craniofacial Surg, 2009-Vol 20- issue 5;pp13521355

6.Masaki F, Kazuhiko Y et al Clinico -Statistical study on cleft lip and palate in the past 20 years at the dept of oral \& maxillofacial surgery, Nara Medical University. J of Japanese Cleft Palate Association, 2003,Vol 28;3,pp 338-349,

7. Mossey P.A,Little J, Epidermiology of oral clefts,an international perspective; In wyszuski DF, Cleft lip and Palate;From Origin to Treatment:New York Oxford University Press;2002, ch42,pp127-158

8. GregT,Boyd D,Richardson A The incidence of cleft lip and 
palate in Northern Ireland from 1980 to $1990 \mathrm{Br}$ J. Orthodo ntics.1994Nov;21(4):387-392

9. Yu Fang Liao,Michael-Mars Hard palate repair timing and facial growth in cleft lip and palate: A systematic review the cleft palate -Craniofacial Journal. 2006,Vol43:5:pp 563-570

10. Habel A,Sell D Management of cleft lip and palate. Arch of disease in childhood, 1996:74;360-364

11. Millard DR, The embryonic rationale for primary correction of the cleft lip and palate Annals Roy Coll Surgery Eng, 1994:76;150-60

12 Mulliken JB, Correction of the bilateral cleft lip: Review,Revision and Reflection J. Craniofacial Surg 2003:14(5)609-20

13. Nakajima T,Ogata H,Sakuma H. Longterm outcome of si- multaneous repair of bilateral cleft lip and nose (a 15 year experience) BrJ.Plast .Surg 2003:56(3)205-17

14. Furlow Lt.Jr Cleft palate repair by double opposing Z -plasty plast. Reconstr. Surg 1986;78(6):728-38

15. Perko M. Two stage Palatoplasty In: Bardach J,Morris Lt L, Multidisciplinary management of cleft lip and palate. Ist edition. WB. Saunders Co:1991:311-

16. Demey A,Vadond Seyed ,F Demol, Early post operative complication in primary cleft lip and palate surgery Eur. J. Plastic Surg.; 1997; 20(2):77-79

17. V lees, R Pigott Early post operative complications in primary cleft lip and palate surgery Br. J. Plastic Surg. 1992; 45(3):232234 